\title{
Water Fluoridation in Israel: Ethical and Legal Aspects
}

\author{
Shlomo P. Zusman, DMD, MSc(DPH), MPA ${ }^{1}$
}

\begin{abstract}
Fluoridation of community drinking water for prevention of dental caries commenced in the United States in 1945 and has become one of the major achievements of public health according to the US Center for Disease Control. It has been adopted widely, mainly on voluntary basis by local authorities responsible for community water supplies. Fluoridation is the most effective method to prevent dental caries at the community level and promotes equality because all benefit regardless of their awareness or the importance they give to dental health. However, fluoridation is still regarded as an unnecessary and allegedly harmful intervention by a few dedicated opponents who express their views through aggressive postings on the internet and all other channels of communication.

After many years of failed attempts to implement "voluntary" fluoridation by local authorities, Israel implemented mandatory fluoridation legislation in 2002. Public controversy and persistent opposition led to challenges to the legislation passed by the Israeli Knesset (parliament) and brought the matter to the Supreme Court. The Court confirmed the Ministry of Health's responsibility for the health of the public and that the evidence presented indicated fluoridation was a safe and reasonable measure to help achieve that mandate. Fluoridation has since been implemented across the country based on this legislative mandate. In 2012, a private bill to stop fluoridation was defeated in the Knesset. This case represents an ideological struggle between opponents to a public health measure and its resolution in a higher court decision in favor of safe and effective public health benefits and in legislation.
\end{abstract}

Key Words: Community water fluoridation; ethics in public health, legislative mandate in public health, Israel

Suggested Citation: Zusman SP. Water Fluoridation in Israel: ethical and legal aspects. Public Health Reviews. 2012;34: epub ahead of print.

\footnotetext{
${ }^{1}$ Director of Dental Health, Ministry of Health of Israel.
}

Corresponding Author Contact Information: Shlomo P. Zusman at shlomo.zusman@moh. health.gov.il; Director of Dental Health, Ministry of Health, 157 Jaffa Road, 91010 Jerusalem, Israel. 


\section{INTRODUCTION}

At the beginning of the $20^{\text {th }}$ century, the dentist Frederick McKay noticed the brown staining of the teeth of some of his patients in the town of Colorado Springs, Colorado in the United States. The brown teeth, originally known as "Colorado Brown Stain" and later termed "mottled enamel", were more resistant to caries. ${ }^{1}$ McKay along with G.V. Black conducted an epidemiological study in 26 communities. Their assumption was that the mottling was caused by something in the water, but it was not clear what. In 1931, H.V. Churchill, a chemist working for an aluminum manufacturer (ALCOA), was concerned that people might think that the color was caused by the aluminum. He analyzed the water from the areas where McKay reported the staining, looking at several elements and found high levels of fluoride (between 2 and $13 \mathrm{ppm})^{2}$ and the name of the occurrence was changed again to "dental fluorosis".

The head of the Dental Hygiene Unit at the US National Institute of Health, H. Trendley Dean conducted his famous study and in 1942 published the connection between fluoride concentration in water and prevalence of dental caries. He determined that concentrations of fluoride at one ppm reduced caries while fluorosis was minimal. ${ }^{3}$

The first artificial fluoridation was carried out in 1945, in Grand Rapids, Michigan, followed by Brantford, Ontario, Canada. The measure was researched and shown to be effective and safe. One of the early studies, ${ }^{4}$ published in 1956, shows the difference in the caries prevalence between the fluoridated Newburgh and non-fluoridated Kingston townships in New York State after ten years. The study did not find any adverse health effects.

In 1969, WHO declared that water fluoridation was safe and "it is the most efficient way to prevent dental caries". ${ }^{5}$ In 1999, the US Centers for Disease Control included fluoridation of community water supplies as one of the ten great achievements of public health of the 20th century ${ }^{6}$ along with vaccination, food safety (such as pasteurization of milk, fortification of basic foods with essential minerals and vitamins), antibiotics, improved occupational health and road safely, smoking reduction and others.

Besides 50 million people enjoying the benefits of naturally fluoridated water, about 370 million drink fluoridated water in 27 countries. ${ }^{7}$ In the US, "by the end of 1992, 10,567 public water systems serving 135 million persons in 8,573 US communities had instituted water fluoridation. Approximately 70 percent of all US cities with populations of greater than 100,000 used fluoridated water." ${ }^{\text {P }}$ Portland, Oregon decided to join in as recently as this year, 2012. ${ }^{9}$ 
In the United Kingdom, "Birmingham is fluoridated, Manchester is not, after years of public controversy. The dental health of Birmingham children is among the best in the UK while that of some Manchester children among the worst. This inevitably translates into greater misery, pain and increased recourse to general anaesthetic extractions in the high caries area." 10 According to the British Fluoridation Society, about six million people drink fluoridated water in the UK and Southhampton will be fluoridated soon. ${ }^{11}$

There are mandatory fluoridation requirements in Ireland, Singapore, Hong Kong, several US states and most Australian states. The majority of European countries do not fluoridate water, as often cited by the antifluoridationists; fluoridation is legal in European countries but not implemented by local authorities.

\section{HISTORY OF FLUORIDATION IN ISRAEL}

In 1962, Mekorot, the Israeli national water company, prepared a list of fluoride levels in community water supplies across the country showing fluoride levels in the whole region north of Beersheba to be very low. However, when a parliamentary question on the advisability of water fluoridation was asked in the Knesset (the Israeli parliament) in December $1967,{ }^{12}$ the official answer of the Minister of Health was: "The majority of the population drinks water with adequate fluoride levels. Dental caries is not a serious problem; at any rate the prevalence is not high enough to consider fluoridation.” This reply, drafted by the Director-General of the Ministry, was based on studies in the early 1960s, which purported to show a low level of caries. At that time there was no dental department in the Ministry of Health, and the matter was not pursued.

In 1970 the Ministry of Health established a Department of Dental Health. Studies carried out by the Department quickly showed that dental health was poor with over 90 percent of children in the country suffering from dental caries. Rampant caries in pre-school children was the norm. The public dental service was very rudimentary; free dental care to children and other priority groups was available only in Jerusalem and Tel Aviv, and dental awareness among the public was very low. Fluoride toothpastes were not yet on the market and there was almost no use of fluoride supplements. There was one dental school, which produced about 30 dentists a year, but there was no course for dental hygienists. The first course for training chair side assistants had just started. The Ministry budget for dental services was miniscule (about USD \$20,000). Immigration to Israel was continuing at a high level and included large numbers of people with a high rate of dental 
disease, little motivation and no money to pay for dental care. Under such conditions the only realistic way of improving dental health was through prevention. The new dental department thus made water fluoridation its highest priority.

In 1970, the Minister of Health was authorized to promulgate regulations regarding drinking water quality. ${ }^{13} \mathrm{He}$ appointed an expert committee to prepare the regulations. The committee, in its report ${ }^{14}$ from 1973, confirmed that fluoride in water is beneficial. Except for the Negev desert region in the south, where there were high levels of natural fluoride, reaching three ppm in some places, fluoride levels in most of the country were well below optimal levels. The committee recommended that an appropriate level of fluoride should be in the water according to the climatic area. Nevertheless, the regulations ${ }^{15}$ permitted but did not mandate the water supplier to fluoridate those water supplies deemed deficient in fluoride.

As in most other countries, Israel did not have separate domestic and industrial or agricultural water supplies. In Israel the national water system was considered to be primarily a resource for agricultural use and the Water Commissioner was under the aegis of the Ministry of Agriculture. The Ministry of Health has only limited authority on water issues.

A national plan for water fluoridation was prepared in 1976, ${ }^{16}$ approved by the Ministry and the Parliament in 1977 and its start budgeted in 1978.

\section{IMPLEMENTATION}

In 1979 the Health Education Department of the Ministry published a booklet, mainly for local authorities, explaining fluoridation. ${ }^{17}$ This booklet included endorsements from all the major medical and dental institutions in Israel and translations into Hebrew of endorsements by international bodies. One-to-one meetings were held with mayors, council chairmen, politicians and health correspondents in order to explain the value and importance of fluorides in human health.

Considerable attention was given to educating health care workers (HCWs). Lectures, study days and symposia were organized for public health nurses, nursing students, dental students and others. Indeed this policy continues to this day in order to ensure that HCWs are kept up to date with information on caries prevention.

Experience in North America and some European countries had shown that public referenda more often than not resulted in the eventual rejection of water fluoridation. Crain, Katz and Rosenthal wrote in 1969:18 “ . . referenda breed further referenda, and win or lose; referenda breed defeat both in the 
referendum cities and their neighbors." ${ }^{18(.269)}$ "Controversy breeds defeat. The presence of controversy discourages the government from adopting fluoridation and puts pressure on the government to hold referenda."18(p.136)

Referendum is not used as a governance tool in Israel; nevertheless it was recognized that the fluoridation plan might be opposed by some. The main reason for this is the basic mistrust that some sections of the public have in anything that is done by the government. Paternalism and beneficence by the government were seen as infringement and are not much appreciated in an atmosphere emphasizing freedom and the right of the individual to determine his or her destiny as he or she thinks fit.

The dental profession in Israel was supportive of extending fluoridation to the whole population recognizing the poor state of dental health of children in the country. However, the dental association often easily gives up the struggle as independent dental professionals have neither the patience nor the financial resources or the motivation to continue to fight in the face of constant pressure from small but dedicated groups who oppose this measure.

Lobby groups from the US, such as the Coalition for Pure Water, flooded ministers, mayors and members of parliament with written material purporting to prove that adding fluoride to the water bears many health risks. The Association for the Health of the Public entered the arena in February 1979 and demanded, in the name of democracy: "to halt immediately all preparations to introduce fluoride in the water until it has been established in court that the Ministry has the right to do so, and not to coerce this on the public against its will."

The ministry felt that it did not make sense to engage in a professional/ scientific debate at an emotional or political level. Instead of engaging in debates in the mass media, a program that presented the scientific facts and arguments objectively was prepared and presented as part of a total plan for oral health. The importance of fluoridation was not overstressed; those promoting the measure were seen as reasonable people and not extremists. It was pointed out that fluoride is not a universal dental panacea and that fluoridation is of value as a public health measure only when it is an integral part of a total program for reducing and controlling oral disease. It is not the only way of preventing caries but it is the most cost-effective method at a community level. It was acknowledged that in other countries there had been a substantial reduction in dental caries in recent years even without water fluoridation. It was suggested that this decrease would have been much greater and at lower cost to the taxpayer had fluoridation been implemented. Only a very rich country can afford not to fluoridate its drinking water.

Confrontations in the media with antifluoridationists were avoided. It was considered preferable to refuse to comment on a newspaper article on 
the grounds that public interest dies down quickly if there is no response. Likewise, participation in television 'talk shows' was resisted, however tempting it seemed. ${ }^{19}$ The anti-fluoridation lobby was addressed politely as being well meaning but sadly misinformed as discourtesy and verbal violence often gives rise to hysteria rather than intelligent discussion.

In 1980, WHO assigned a technical expert as a consultant to the Israeli Ministry of Health in the engineering aspects of fluoridation. Two visits were made and the technical problems were discussed. ${ }^{20}$ The consultant was later appointed as Chief Fluoridation Engineer in the Ministry, a post that he held until retirement in 2004.

The first water fluoridation plant opened in Jerusalem in 1981. Jerusalem was chosen because its water engineer was committed to fluoridation and not because it is the capital, nor because it is the Holy City. This plant was largely funded by the Ministry of Health. It was built on the main pipeline, which, at that time, supplied water to 40 percent of the population of the capital.

\section{PROBLEMS IN IMPLEMENTATION}

The first plant operated intermittently until 1984 when it was closed down for the following reasons:

1. The building had been carried out by a contractor with little understanding and no experience of fluoride plant engineering, and the plant suffered from inherent faults.

2. Maintenance was the task of the city water department and the staff on site was not motivated, nor was it compensated adequately. As a result the plant frequently broke down.

3. The plant was designed in 1977 and by 1984 the population of Jerusalem had increased considerably. A new larger pipeline had to be brought into the city. The former main water supply to Jerusalem had by this time become a less important source, supplying only 12 percent of the water to the city. It was therefore no longer able to play an effective role in fluoridation and a new plant had to be constructed to serve the new larger pipeline.

This was very convenient, as it turned out, and the new plant built in 1988, was trouble free for ten to eleven years.

In 1983 a 'model plant' for a rural collective village (kibbutz) was constructed. It was intended to serve as an example of low cost fluoridation for very small communities. This plant, paid for by the Ministry, was run and maintained by a member of the kibbutz who was involved in water quality, committed to fluoridation and prepared to devote time to the project. 
Based on the poor outcome of the original plant in Jerusalem and the success of the kibbutz installation, the following conclusions were drawn:

1. The cooperation of the local government and especially of the people involved directly in operation is important for project success.

2. The design of new plants has to be checked and approved at all stages by the Ministry. For this purpose a Water Fluoridation Engineer was appointed.

3. A plant would only be approved if a competent body would be running it. No fluoridation is preferable to unprofessional maintenance.

\section{NEW PUBLIC POLICY}

As a result, the following policy changes were made:

1. After the agreement of the Municipality, in order to ensure control, the Ministry would pay for the general and detailed planning of the fluoridation plant.

2. The cost of building the installation would be shared between the Ministry and the local authority.

3. The operating cost would be met by the local authority (which sells the water to the consumer).

In 1988 there were seven plants in the country, and about a third of the population enjoyed the benefits of appropriate fluoride levels. However, even this policy did not always work in practice. In the largest population center of the Tel Aviv area (i.e., the Gush Dan project) one of the largest fluoridation plants in the European region at the time was planned, catering to a population of nearly one million persons and including six municipalities. It was felt that the chances of ever reaching agreement between the various local authorities for sharing the cost would be small. The Dental Department therefore decided to by-pass all negotiations with the municipalities by using the enabling regulations of 1974 and the Ministry agreed to cover the total cost of planning, building and running of the plant and to indemnify Mekorot against any claims. Mekorot agreed to handle this project and the Ministry of Health has been paying the operating costs ever since.

Another example was, Kiryat Shmona, a small northern border town of very limited resources. It was unable to pay its share of the cost of the plants. The Ministry and the Israel Fluoridation Society succeeded in finding a donor who covered most of the town's share. The municipality meets the running costs, which are small.

Besides the problems with the cooperation of the municipalities, there have been delays in the implementation of the national fluoridation program due to an ongoing conflict between Mekorot and the Ministry on the 
wording and conditions of the contract for the building of each plant. There was no other agency in Israel with the professional and technological expertise and manpower resources needed to undertake major fluoridation projects at the very high professional level at which Mekorot operates. The policy had to be updated again.

\section{NEW PUBLIC POLICY II}

In 1990, the Water Commissioner declared that adequate fluoride levels would be considered as part of the 'drinking water standards' and the running cost of fluoridation would be included in the price of water to the consumer. Mekorot, who was supplying about 70 percent of the water, was in favor of this approach, preferring not to have to sign different contracts for each plant or to deal with collection from each municipality separately. Even the vast majority of local authorities were in favor, as Mekorot would do the fluoridation without them paying and they still would collect the cost from the consumer in the normal water bill. It took time until this could be implemented. However, the powerful, non-partisan agricultural lobby was strongly opposed to any increase in the cost of water to the consumer.

Eight years passed from the Water Commissioner's decision until the regulations were amended in December 1998. The water supplier was then obliged to supply fluoridated water to every community with more than 5,000 inhabitants. Implementation was supposed to be completed by June 2001 .

\section{PROBLEMS IN IMPLEMENTATION II}

In 2001, there were 62 plants serving about half of the population. Mekorot having not met the deadline of June 2001, asked for and received a year of extension. They did not meet that date either. Despite this, at every opportunity they publicized the national fluoridation program.

The publicity caught the attention of the antifluoridationists in Israel and abroad. Their claims found sympathy with those local authorities that were independent water suppliers. These municipalities had their own wells, often more than one, and now they had to build and maintain many small fluoridation plants. The money they collected was insufficient to ensure the kind of profit that Mekorot made through constructing large plants for large populations. The one-year extension given to Mekorot was portrayed by the antifluoridationists as if the Ministry had had second thoughts.

This time, antifluoridationist material was sent from the US via e-mail to every minister and every member of the parliament. A hearing on the 
issue was held in the Parliament's Health committee. The representatives of the Ministry of Health did not agree to any further delay or further consideration or expert committees. In May 2002, the Municipality of Herzlia (a Tel Aviv suburb) and the local government union lodged an appeal against the Ministry of Health, the Ministry of Environment, and the Health Committee of the Parliament and Future Generations Commissioner of the Knesset at the Supreme Court. The main claims were:

1. Fluoridation causes ill health, damages several systems: nervous, kidneys, bones, especially among those with impaired immune system and chronic diseases such as diabetes (who drink a lot of water) or people on dialysis;

2. Fluoride in the water is like mass-medication against Patient's Rights Law;

3. Fluoride is a poisonous chemical; therefore its addition to the water is prohibited by law; If not considered a poisonous chemical, it is a food additive so it cannot be added to the water;

4. It will cause ecological damage;

5. There is scientific controversy regarding the appropriate dosage;

6. Many countries in the world oppose fluoridation;

7. It is not cost-effective; and

8. It will damage the water piping system because it is corrosive. The lead from the pipes will be digested by the children and there will be more cases of Attention Deficit Hyperactivity Disorder (ADHD).

In September 2002, on the second hearing, the appeal was withdrawn on the advice of the Supreme Court. Since then the lobby is still active and vociferous with extreme and emotional attacks sometimes crossing red lines, such as with the publication, "From Fluoride to Hydrofluorosilycic Acid. The Big Absurd: From the Nazi Era to Coercion in Israel." ${ }^{21}$ Every now and then a member of parliament shows interest in the subject and is influenced by such material.

In 2004, the Ministry of Health appointed an expert committee (the Adin Committee) to update the standards for potable water. Fluoride was dealt with at the chemistry sub-committee. The final recommendations of the committee were somewhat different than the sub-committee's: the acceptable concentrations were upheld, desalinated water has to be fluoridated, but regarding the rest of the country, it should be left to the decision of each local government. This last recommendation was beyond the mandate of the committee. Professionally speaking, central (big) plants dealing with water are better than small, local plants.

In 2007, WHO expressed once again its support of water fluoridation in a General Assembly resolution. ${ }^{22}$ In 2012, a private bill to prohibit fluoridation of water was defeated in the Knesset with a large margin. 


\section{THE ETHICAL DEBATE}

The main ethical arguments against water fluoridation are:

1. Infringement of personal freedom of consuming water without fluoride;

2. Infringement of personal freedom of consuming 'natural' water without additives; and

3. Coercing people to consume the water as supplied.

There are however strong ethical arguments for this public health measure:

1. Reducing the risk of ill health ${ }^{23}$;

2. Special care for the health of children (who cannot speak for themselves); and

3. Reducing health inequalities.

There is no basic human right for water without fluoride, as there is no such water on earth. The debate is about the level of fluoride and there is no ethical right to deprive others from the benefits of the measure for the preference of few. It is notable that there is no demand to lower fluoride levels from optimal where it is naturally occurring.

The basic issue that shapes the ethical debate is the value attributed to dental disease. When dental disease was prevalent, loss of teeth was regarded as inevitable with aging. Times and values have changed, Today, the importance of oral health and appearance is high for social as well as physical functioning. Dental disease and edentulessness are preventable and should be prevented.

Water fluoridation is a public health measure suitable for Israel due to the piped water system and the dental disease levels. Evidence shows that this measure is beneficial to Israeli citizens in general and children in particular, with little or no side effects.

\section{THE FUTURE}

When fluoridation costs were included in the price of water to the consumer, Mekorot changed the method of fluoridation from local plants to the construction of three large regional water fluoridation plants on the National Water Carrier, which supplies over 70 percent of community water in the country. In addition individual plants are planned for those places not directly supplied by the National Water Carrier. When the program is completed Israel will have approximately 160 plants. 


\section{DENTAL CARIES IN ISRAELI CHILDREN}

As part of the baseline study for Health for All for the year 2000, a nationwide survey was carried out in 1989 to assess the prevalence of dental caries in a representative sample of five- and 12-year-old children in urban and rural areas. ${ }^{24}$ Among the five-year-olds, 41.3 percent were caries free, decayed, filled or indicated for extraction deciduous teeth (dift) $=$ 2.72. In the 12-year-old population, $21.2 \%$ were caries free with decayed, missing, filled permanent teeth $($ DMFT $)=2.99$ (Table 1$)$.

These results were lower than previous findings. The differences between fluoridated and non-fluoridated areas were striking both in percentage of caries-free children and DMFT/dift scores. No significant differences were found between urban and rural areas.

In 2002, in a further national study, ${ }^{25} 1,327$ 12-year-olds were examined, 46 percent were found to be caries free and DMFT $=1.66$. In fluoridated areas 50.3 percent were caries free with DMFT $=1.39$; in non-fluoridated 42 percent were caries free with DMFT $=1.83$ (Table 1). A 24 percent difference between the two areas in average DMFT, and 20 percent difference in prevalence. The York study in the UK found a median difference of 14.6 percent in caries free between fluoridated and non-fluoridated areas. ${ }^{26}$

Table 1

Percentage of dental caries free and DMFT/dift scores among 5-year-olds and 12-year-olds in a nationwide survey in 1989 and among 1,327 12-year-olds in a national study in 2002

\begin{tabular}{l|l|c|c|c|c}
\hline Year & & \multicolumn{2}{|c|}{ 5-year-olds } & \multicolumn{2}{c}{ 12-year-olds } \\
\hline & & Percent caries free & dift & Percent caries free & DMFT \\
\hline $1989^{24}$ & Non-fluoridated water & $32 \%$ & 3.89 & $12.4 \%$ & 4.39 \\
\hline & Fluoridated water & $51.4 \%$ & 1.75 & $23.2 \%$ & 2.65 \\
\hline & Overall & $41.3 \%$ & 2.72 & $21.2 \%$ & 2.99 \\
\hline $2002^{25}$ & Non-fluoridated water & - & - & $42 \%$ & 1.83 \\
\hline & Fluoridated water & - & - & $50.3 \%$ & 1.39 \\
\hline & Overall & - & - & $46 \%$ & 1.66 \\
\hline
\end{tabular}

It seems that the decline in 12-13 years was bigger in the non-fluoridated area then in the fluoridated one, and the difference between the two is smaller. Is fluoridation losing its effect? I don't think so. 
First of all, in all areas fluoridated toothpaste is in use, hence the decline in the non-fluoridated area. Furthermore, 50 percent of the country was fluoridated in 2002 in several distinct areas, not in one, geographically contiguous area. Every fluoridated area has a 'halo effect' on the areas around it that were not fluoridated, but were influenced secondarily by the fluoridated area. The children may study in the adjacent town, visit friends or family and are exposed to fluoridated water too. Some of the food industry is located in fluoridated areas and their products are consumed in non-fluoridated areas. As a result, there is fluoride found in at least part of the non-fluoridated areas.

We expect that in the next national survey we will find a still lesser difference between the fluoridated areas and the non-fluoridated "islands" that will remain. So, fluoridation is working.

There has been a decline in caries prevalence in Israel in the last 20 years; Israel is in a mid-position among the European countries. We have not changed our relative ranking; we were also in the middle ten and 20 years ago. Dental health has improved in other European countries too and few of them fluoridate the water. In a similar period of time, there has been a much more dramatic improvement in some European countries. Fluoride is not a 'vaccine', it does not give immunity to caries, but it raises the resistance of enamel to acid attack. Fluoridation has to be complemented by dental health education and dietary counseling to lower sugar consumption in the population, especially for children.

\section{FLUOROSIS}

A study some years ago showed that there was some fluorosis in the Negev region where natural fluoride levels are high as is the mean maximum daily annual temperature. ${ }^{26}$ A further study on fluorosis in Israel ${ }^{27}$ in 1998 indicated the presence of mild fluorosis in "optimally" fluoridated areas as well as in non-fluoridated areas. The same findings were seen in the National survey in 2002. This may suggest that the fluorosis is not caused by the water fluoridation, but by other source of fluoride.

\section{CONCLUSION}

The Ministry of Health Dental Department over many years has managed to convince the decision makers, public opinion that water fluoridation was good policy because we believed this to be needed, effective and safe, as well as the right thing to do. Despite individual convictions, one must take 
a critical approach to issues from time to time. Fluoridation in Israel has produced striking reductions in the dental caries experience of children.

Currently the water system enables 75 percent of the population to enjoy the benefits of fluoridated water. Proposed new schemes will increase the coverage to 85 percent.

The ethical issue is still debated and vigorous opposition is raising claims, butwe must be led to protect the health of children and adults, especially those with less access to dental care and overuse of sugar in various forms. Non-implementation is a bigger ethical issue when the evidence is so clearly established.

\title{
Acronyms List:
}

dift $=$ decayed, filled or indicated for extraction deciduous teeth

DMFT $=$ decayed, missing, filled permanent teeth

HCWs $=$ health care workers

\begin{abstract}
About the Author: Dr. Shlomo P. Zusman is a Specialist in Dental Public Health with substantial experience in strategic planning, policy development and advocacy, project and program design, professional human resource development and allocation. Dr. Zusman has taken part in nationwide studies on the effects of fluoridation on dental carries in children in Israel. He lectures on dental disease prevention and dental public health as well as bioethics and dental law. Since 1998 he serves as the Director of Dental Health at the Israeli Ministry of Health.
\end{abstract}

Conflicts of Interest: None declared.

\section{REFERENCES}

1. McKay FS. Relation of mottled enamel to caries. J Am Dent Assoc. 1928;142937.

2. Churchill HV. Occurrence of fluorides in some waters of the United States. J Ind Eng Chem. 1931;23:996-8.

3. Dean HT. On the epidemiology of fluorine and dental caries. In: Gies WJ, (editor). Fluorine in Dental Public Health. New York, NY: New York Institute of Clinical Oral Pathology; 1945. p.19-30.

4. Ast DB, Schlesinger ER. The conclusion of a 10-year study of water fluoridation. Am J Public Health. 1956;46:265-71.

5. World health Organization. Fluoridation and Dental health. WHO. 23 July 1969.

6. Centers for Disease Control and Prevention. Ten great public health achievements. MMWR Morb Mortal Wkly Rep. 1999;48:241-3.

7. British Fluoridation Society. One in a Million: the facts about water fluoridation, 3rd edition. March 2012. Available from URL: http://www.bfsweb.org/ onemillion/onemillion2012.html (accessed 31 October 2012). 
8. Centers for Disease Control and Prevention. Achievements in public health, 1900-1999: fluoridation of drinking water to prevent dental caries. Morb Mortal Wkly Rep. 1999;48:933-40.

9. KATU.com Staff and Associated Press. Portland approves fluoride: 'science is on the side of fluoridation'. 12 September 2012. Available from URL: http:// www.katu.com/news/local/Portland-City-Council-to-vote-on-fluoride169476836.html (accessed 31 October 2012).

10. Mullen J. History of water fluoridation. Br Dent J. 2005;199:1-4.

11. No author. Southampton water fluoridation was not unlawful. 11 February 2011. Available from URL: http://www.bbc.co.uk/news/uk-england-hamp shire-12427955 (accessed 31 October 2012).

12. Toubi T. Knesset proceedings parliamentary question no. 3378. Israel. 1967.

13. Laws of Israel. Amendment No.4 to the Public Health Ordinance. 1970. para 52B(a) p.102.

14. Department of Environmental Health. Drinking water quality, report of Advisory Committee, Ministry of Health. 1973. [In Hebrew].

15. Public Health Regulations. Drinking water quality, 3117. Israel; 1974. p.556-65.

16. Kelman AM. Fluoridation of community drinking water. Jerusalem: Department of Dental Health, Ministry of Health; 1976. [In Hebrew].

17. Department of Dental Health. Fluoride in water reduces dental caries. Jerusalem: Ministry of Health, Department of Health Education; 1979. [In Hebrew].

18. Crain RL, Katz E, Rozenthal DB. The Politics of Community Conflict: The Fluoridation Decision. Indianapolis, IN and New York, NY. The BobbsMerrill Co., Inc.; 1969.

19. Kelman AM. The social strategy of fluoridation - The Israel Case Study. National Workshop on Health Service Planning and Management. Ministry of Health; 1982.

20. Grinplastch BS. Assignment report - fluoridation of water supplies in Israel. WHO; 1982.

21. Atzmon I. From fluoride to hydrofluorosilycic acid. The big absurd: from the Nazi era to coercion in Israel. 2002.

22. Sixtieth World Health Assembly. WHA60.17. 23 May 2007.

23. Nuffield Council on Bioethics. Public health: ethical issues. London; 2007.

24. Zadik D, Zusman SP, Kelman AM. Caries prevalence in 5- and 12-year-old children in Israel. Community Dent Oral Epidemiol. 1992;20:54-5.

25. Zusman SP, Ramon T, Natapov L, Kooby E. Dental health of 12-year-olds in Israel-2002. Community Dent Health. 2005;22:175-9.

26. Milgalter N, Zadik D, Kelman AM. Fluorosis and dental caries in Yotvata area. J Israel Dent Assoc. 1974;23:104-9.

27. Zadik D, Kelman AM, Vered Y. Prevalence and severity of fluorosis in Israel. J Israel Dent Assoc. 1998;15:13-6. 